\title{
Distribution of bioactive factors in human milk samples
}

Reka A. Vass ${ }^{1}$, Agnes Kemeny ${ }^{2,3}$, Timea Dergez ${ }^{4}$, Tibor Ertl ${ }^{5}$, Dora Reglodi ${ }^{1}$, Adel Jungling ${ }^{1}$ and Andrea Tamas ${ }^{1 *}$

\begin{abstract}
Background: Breast milk provides nutrition for infants and also contains a variety of bioactive factors that influence the development of the newborn. Human milk is a complex biological fluid that can be separated into different layers (water phase and lipid phase with its component water and lipid fractions). It can affect the developing human body along the whole length of the gastrointestinal tract, and through the circulation, its factors may reach every organ.

Methods: In the present study, we analyzed milk samples collected monthly for 6 months from 16 mothers from the $4^{\text {th }}$ week postpartum between 2014 and 2016 in Baranya County, Hungary. The 96 samples provided us information about the fluctuation of certain bioactive factors during the first 6 months of lactation. We investigated with Luminex technology the concentrations of several cytokines (CD40, Flt-3L), chemokines (MCP-1, RANTES, GRO, MIP-1B, MDC, eotaxin, fractalkine), and epidermal growth factor (EGF). Paired t-tests and one-way ANOVA followed by Bonferroni post-hoc tests were used to compare the data.

Results: We detected the presence of each bioactive factor in every layer of the milk samples during the first 6 months of breastfeeding in widespread concentration ranges. In the case of GRO, MIP-1B, MDC, Flt-3L, fractalkine, and eotaxin, the concentrations were constant during the first 6 months of lactation. The water phase of human milk contained higher factor concentrations compared to both fractions of the lipid phase for most factors (except eotaxin and MIP-1ß). The concentrations of CD40, EGF, MCP-1, and RANTES in the first 3 months were significantly different compared to the values detected between $4^{\text {th }}$ and $6^{\text {th }}$ months. In the water phase, the level of MCP-1 was significantly decreased, while all of the other factors increased during the $4^{\text {th }}$ through $6^{\text {th }}$ months. We found significantly higher EGF, GRO, and RANTES levels in the water fraction compared to the lipid fraction of the lipid phase.

Conclusions: The novel findings of this investigation were the presence of Flt-3L and MDC in all layers of breast milk, and nearly all bioactive factors in the lipid phase. Due to their widespread physiological effects these factors may have an essential role in organogenesis.
\end{abstract}

Keywords: Bioactive factors, Breast milk, Luminex, MDC, Flt-3L, Water phase, Lipid phase, Cytokines, Chemokines, Growth factor

\section{Background}

Human milk is a complex biological fluid uniquely suited to the infant. Its quantity and composition are constantly changing during lactation and are influenced by numerous factors [1-3]. It promotes survival and development of the newborn due to its nutritional composition and non-nutritive bioactive factors, including growth factors, hormones and immunological factors, such as chemokines

\footnotetext{
*Correspondence: andreatamassz@gmail.com

'Department of Anatomy, MTA-PTE PACAP Research Group, Centre for

Neuroscience, Medical School, University of Pécs, Pécs, Hungary

Full list of author information is available at the end of the article
}

and cytokines with different physiological effects. The distribution and level of the bioactive factors vary widely in the milk [4, 5], and the exact role and effects of these factors during postnatal adaptation are still under investigation. These biologically active molecules are proven to protect the newborn from different infections affecting the respiratory and gastrointestinal tract $[6,7]$ and have an important role in gaining immunocompetence $[8,9]$. In addition to the immunological effects they contribute to organogenesis and they are essential for the development

(c) The Author(s). 2019 Open Access This article is distributed under the terms of the Creative Commons Attribution 4.0 International License (http://creativecommons.org/licenses/by/4.0/), which permits unrestricted use, distribution, and 
and adequate functioning of the nervous, gastrointestinal and cardiovascular systems [10].

Bioactive components of human milk come from a variety of sources; some are produced and secreted by the mammary epithelium or by cells carried within the milk, while others are drawn from maternal serum and transferred across the mammary epithelium by receptor-mediated transport [10]. Previous studies have proven that human breast milk is segregable into water and lipid phases using different separation techniques. Preclinical and clinical studies have analyzed mainly the water phase of milk. However, breast milk has a complex lipid architecture [11] that forms a special biological colloidal system [12]. Typically, the fat content of mature human milk is about $4 \mathrm{~g} / \mathrm{dL}$. The lipid phase can be further divided into water and lipid fractions with additional separation techniques. The lipid fraction contains milk fat globules (MFG), secreted by the mammary epithelial cells; and their size varies from 0.2 to more than $15 \mu \mathrm{m}$ [13]. The milk fat globules secreted into breast milk are made up of four layers (from inside, in order): a single layer of polar lipids and proteins, an entrained cytoplasm layer (10-20 nm wide) and a double layer of polar lipids, proteins, glycoprotein and cholesterol $[14,15]$. The inner monolayer membrane originates from the endoplasmic reticulum, while the outer bilayer originates from the apical plasma membrane. The bioactive factors are found in the cytoplasm layer; this way they are protected during the transition through the gastrointestinal tract. Therefore, the contents of MFG are able to directly influence the composition of microbiota or colonization of the gut and also to absorb into the circulation $[16,17]$.

Only limited data are available about the content of bioactive factors during the first months of lactation [10]. Therefore, the aim of the present study was to examine the presence and changes in concentration of different bioactive factors during the first 6 months of lactation, which is the most critical period of postnatal adaptation and when exclusive breastfeeding is recommended. Our applied separation protocol allows us to separately analyze the composition of the water phase and the two fractions of the lipid phase involving the protected cytoplasm layer within the MFG. In our study we focused on the following bioactive agents in the three distinct layers: epidermal growth factor (EGF); cytokines: soluble cluster of differentiation 40 ligand (CD40), and FMS-like tyrosine kinase 3 ligand (Flt-3L); and chemokines: monocyte chemoattractant protein-1 (MCP-1), regulated on activation, normal $\mathrm{T}$ cell expressed and secreted (RANTES), macrophage inflammatory protein-1beta (MIP-1 $\beta$ ), macrophage-derived chemokine (MDC), growth-regulated oncogene (GRO), eotaxin, and fractalkine. Cytokines and chemokines, such as CD40, MCP-1, RANTES, MIP-1 $\beta$, and MDC play important roles in the modulation of immune responses and the regulation of immune cell migration [18-22]. Flt-3L is responsible for hematopoietic stem cell progenitor proliferation [23]. With this effect Flt-3L is involved in the development of the cardiovascular system similarly to GRO, which can stimulate endothelial proliferation during neovascularization [24]. Fractalkine and eotaxin are involved in the neurogenesis and the development of synaptic plasticity $[25,26]$. Some bioactive factors can also help the adaptation of the gastrointestinal system, for example EGF enhances the differentiation and proliferation of enteral cells and the development of cell adhesions between hepatic and intestinal cells [27]. Since these factors have proven widespread effects, it would be beneficial to know their exact distribution in the three separated layers of human breast milk.

\section{Methods}

\section{Study design}

This was a descriptive study in which healthy mothers agreed to provide samples of breast milk for analysis. Data collection commenced at four weeks postpartum, and continued every four weeks until six months postpartum.

\section{Maternal inclusion criteria}

Volunteers had delivered full-term infants by spontaneous active labor; pregnancy, labor, and postnatal adaptation were uneventful. Neither mothers nor infants had infectious diseases during the examined period. Mothers involved in the study took Elevit ${ }^{\circ}$ multivitamin complex and folic acid tablets regularly; they had no special diet during pregnancy; all were nonsmokers. Participants recruited with the help of health visitors of the Unified Health Institutions of Pécs - had normal prepregnancy and postpartum Body Mass Index (BMI) (Table 1). We included only mothers who were able to give milk samples at every time point of the investigation. The mothers used their own pumps to avoid transmission of infection.

Table 1 Characteristics of participants $(n=16)$

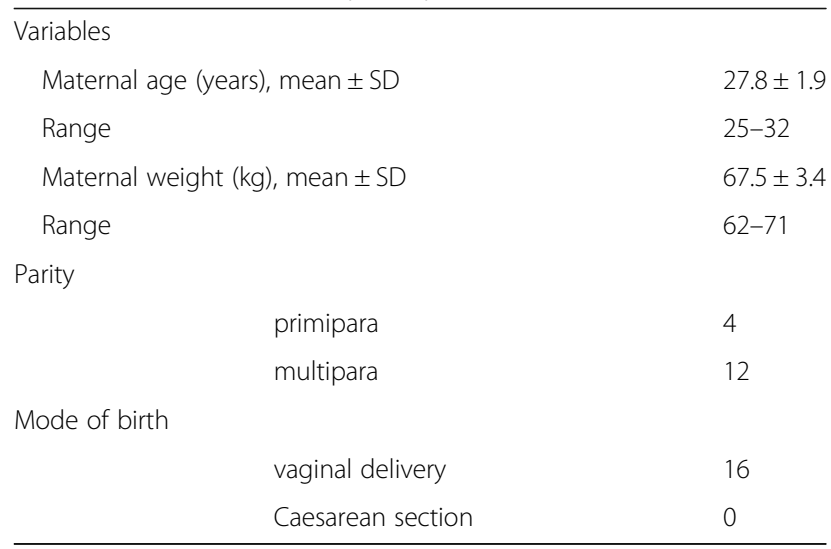




\section{Milk samples}

Milk samples were collected between 2014 and 2016 at the Department of Obstetrics and Gynecology, University of Pécs and at the Unified Health Institutions of Pécs. We collected $5 \mathrm{ml}$ of breast milk from mothers ( $n$ =16) every fourth week during the first 6 months of lactation ( $n=96$ samples). The samples were hindmilk and were collected between $1 \mathrm{pm}$ and $3 \mathrm{pm}$. Participants pumped the entire breast expression into a sterile bottle and $5 \mathrm{ml}$ was poured into polypropylene tubes. We chose early afternoon as the target time for sample collection based on a previous report by Kent et al. [28] showing that milk fat content is lower in night and morning feedings compared to afternoon and evening feedings. Since we analyzed the bioactive content of the lipid layer, we speculated that samples obtained in the early afternoon might be close to representative of the average for all samples throughout a $24-\mathrm{h}$ period. The collected fresh samples were stored at $-20{ }^{\circ} \mathrm{C}$ in sterile polypropylene tubes until analysis.

\section{Separation technique}

In the present experiment, we applied different separation techniques to divide human milk into three different fractions from the original samples [11]. We segregated human milk into water and lipid phases, then the lipid phase was further subdivided into water and lipid fractions. To separate the samples into 3 different layers, milk was centrifuged at $4000 \mathrm{x} \mathrm{g}$ for $15 \mathrm{~min}$ at $13{ }^{\circ} \mathrm{C}$ to remove the pellet which contains the cells. This way we retrieved a water phase and a lipid phase, containing the milk fat globules. The lipid layer was suspended in $10 \mathrm{mM}$ phosphate buffered saline (PBS) ( $\mathrm{pH} 7.4)$ and stored at $4^{\circ}$ $\mathrm{C}$ overnight. Then it was churned with a Turrax at a medium speed until fat and sera were separated. After a brief warming at $38^{\circ} \mathrm{C}$, specimens were centrifuged at $100,000 \mathrm{x} \mathrm{g}$ for $1 \mathrm{~h}$ at $24^{\circ} \mathrm{C}$ to obtain the water fraction and the lipid fraction. Then, the lipid fraction of the lipid phase was suspended in $10 \mathrm{mM}$ PBS (pH 7.4).

\section{Luminex technology}

Luminex Multiplex Immunoassay was performed to determine the protein concentrations of the following cytokines/chemokines using customized Milliplex Human Cytokine/Chemokine Magnetic Bead Panel (Merck Millipore, Burlington, USA): 1. EGF; 2. eotaxin; 3. Flt-3L; 4. fractalkine; 5. GRO; 6. MDC; 7. sCD40L; 8. MCP-1; 9. MIP-1ß; 10. RANTES. Standard curve range for each of these analytes was $3.2-10,000 \mathrm{pg} / \mathrm{ml}$. Sensitivity (minimum detectable concentration in $\mathrm{pg} / \mathrm{ml}$ ) values were: EGF: 2.8; eotaxin: 4.0; Flt-3L: 5.4; fractalkine: 22.7; GRO: 9.9; MDC: 3.6; sCD40L: 5.1; MCP-1: 1.9; MIP-1ß: 3.0; RANTES: 1.2. Following previous optimizations, all samples were tested undiluted in a blind-fashion way and in duplicate. The experiment was performed according to the manufacturer's instructions. Briefly, $25 \mu \mathrm{l}$ of each sample (control and standard) was added to a 96-well plate (provided with the kit) containing $25 \mu \mathrm{l}$ of capture antibody coated, fluorescent-coded beads. Biotinylated detection antibodies and streptavidin-PE were added to the plate after the appropriate incubation periods. After the last washing step, $150 \mu \mathrm{l}$ of sheat fluid was added to the wells, the plate was incubated and read on the Luminex100 instrument. Five-PL regression curve were used to plot the standard curves for all analyte by the xPonent 3.1 software analysing the bead median fluorescence intensity. In the case of eotaxin, Flt-3L, fractalkine, MDC, and RANTES we eliminated from the analysis those data that were questionable because of the detection limits of the assays. In the case of RANTES, some of our data were above the sensitivity limit, but below the standard curve, so these results were calculated by extrapolation of the standard curve. Results are given in mean $\mathrm{pg} / \mathrm{ml} \pm$ standard deviation $[\mathrm{SD}$ ] wet tissue.

\section{Statistical methods}

When we compared the concentration values of the first 3 months to the results detected between $4^{\text {th }}$ and $6^{\text {th }}$ months we applied paired t-tests. One-way ANOVA followed by Bonferroni post-hoc tests were used to compare the concentration of the factors in the different layers during the first or second parts of the examination. Statistical analyses were performed by IBM SPSS Statistics v20.0 (IBM's Corporate, New York, USA). Differences were considered to be significant when $p$ values were $<0.05$. All data are given as mean \pm SD.

\section{Results}

The mothers ranged in age from 25 to 32 years (Table 1). They ranged in weight from 62 to $71 \mathrm{~kg}$; all had normal BMIs. Four mothers were primiparous, the others multiparous. All were delivered vaginally. During the first six months of lactation, we did not detect any time-dependent changes in the concentrations of GRO, MIP-1ß, MDC, Flt-3L, eotaxin, or fractalkine. The average values of these bioactive factors in the water phase and in the two layers of the separated lipid phase are shown in Table 2. We detected significantly higher levels of GRO, MDC, Flt-3L, and fractalkine in the water phase compared to both separated fractions of the lipid phase. No significant differences were detected between the concentration of MIP- $1 ß$ in the water phase and the separated fractions of the lipid phase. We measured significantly higher GRO concentration in the water fraction of the lipid phase compared to the lipid fraction. Eotaxin concentration in the water phase was similar to the lipid fraction, and it was not detectable in the water fraction. We did not detect significant differences 
Table 2 Concentration of bioactive factors during the first 6 months of lactation $[\mathrm{pg} / \mathrm{ml}]$

\begin{tabular}{|c|c|c|c|c|c|}
\hline \multirow[t]{2}{*}{ Factors } & \multirow[t]{2}{*}{ Water phase (W) } & \multicolumn{2}{|l|}{ Lipid phase (L) } & \multirow[t]{2}{*}{$p$ - values } & \\
\hline & & Water fraction (L-WF) & Lipid fraction (L-LF) & & \\
\hline GRO & $5398.36 \pm 2250.44$ & $1927.09 \pm 563.33$ & $652.36 \pm 160.60$ & $\begin{array}{l}\text { W vs L-WF } \\
\text { W vs L-LF } \\
\text { L-WF vs L-LF }\end{array}$ & $\begin{array}{l}<0.0001 \\
<0.0001 \\
0.0003\end{array}$ \\
\hline MIP-1ß & $6.72 \pm 2.58$ & $5.35 \pm 0.57$ & $6.23 \pm 1.44$ & $\begin{array}{l}\text { W vs L-WF } \\
\text { W vs L-LF } \\
\text { L-WF vs L-LF }\end{array}$ & $\begin{array}{l}0.5280 \\
1.0000 \\
1.0000\end{array}$ \\
\hline MDC & $21.48 \pm 16.01$ & $11.83 \pm 8.15$ & $12.25 \pm 8.46$ & $\begin{array}{l}W \text { vs } L-W F \\
W \text { vs } L-L F \\
L-W F \text { vs } L-L F\end{array}$ & $\begin{array}{l}0.0029 \\
0.0069 \\
1.000\end{array}$ \\
\hline Flt-3L & $8.81 \pm 2.36$ & $6.25 \pm 0$ & $6.25 \pm 0$ & $\begin{array}{l}\text { W vs L-WF } \\
\text { W vs L-LF } \\
\text { L-WF vs L-LF }\end{array}$ & $\begin{array}{l}0.0235 \\
0.0235 \\
1.0000\end{array}$ \\
\hline eotaxin & $9.62 \pm 2.54$ & Not detectable & $9.85 \pm 3.89$ & W vs L-LF & 0.9227 \\
\hline fractalkine & $166.84 \pm 81.77$ & $43.29 \pm 23.00$ & $25.27 \pm 7.13$ & $\begin{array}{l}\text { WP vs L-WF } \\
\text { WP vs L-LF } \\
\text { L-WF vs L-LF }\end{array}$ & $\begin{array}{l}<0.0001 \\
<0.0001 \\
0.5774\end{array}$ \\
\hline
\end{tabular}

GRO growth related oncogene; MIP-1ß macrophage inhibitory protein 1ß; MDC macrophage derived chemokine; Flt-3L Flt-3 Ligand

between the separated fractions of the lipid phase in MIP-1ß, MDC, Flt-3L, or fractalkine (Table 2).

We found differences in CD40, EGF, MCP-1, and RANTES concentrations between the first 3 months and at 4-6 months of lactation. The concentrations of these factors in the water phase are presented in Table 3 , and the factor content of the separated lipid phase is shown in Table 4. The CD40, EGF, and RANTES levels in the water phase increased significantly, and the MCP-1 level decreased significantly with time (Table 3$)$. In the water fraction of the lipid phase, levels of all factors were significantly higher in the second (4-6 months) part of the examination period. In the lipid fraction of the lipid phase, MCP-1 and EGF increased with time, and CD40 and RANTES did not change significantly (Table 4).

In the case of four factors - CD40, EGF, MCP-1, and RANTES, - we detected significant changes between the different layers of breast milk during the first (1-3 months) and the second (4-6 months) parts of the examination period. Comparing to the three layers of

Table 3 Concentration of bioactive factors presented in the water phase of human milk during the first 6 months of lactation $[\mathrm{pg} / \mathrm{ml}]$

\begin{tabular}{|c|c|c|c|}
\hline \multirow[t]{2}{*}{ Factors } & \multicolumn{2}{|l|}{ Water phase [W] } & \multirow{2}{*}{$\begin{array}{l}p \text {-values } \\
1-3 \text { vs } \\
4-6 \\
\text { months }\end{array}$} \\
\hline & $1-3$ months & 4-6 months & \\
\hline CD40 & $50.17 \pm 2.76$ & $65.77 \pm 1.57$ & $<0.0001$ \\
\hline EGF & $2234.95 \pm 790.45$ & $4064.33 \pm 953.71$ & $<0.0001$ \\
\hline MCP-1 & $2986.49 \pm 937.31$ & $306.66 \pm 146.57$ & $<0.0001$ \\
\hline RANTES & $3.0 \pm 0.75$ & $5.18 \pm 1.56$ & 0.0273 \\
\hline
\end{tabular}

CD40 cluster of differentiation 40; EGF epidermal growth factor; $M C P-1$ macrophage chemokine protein-1; RANTES regulated on activation, normal T cell expressed and secreted breast milk, the water phase contained significantly higher levels of CD40, EGF, and MCP-1 during the first 3 months. We detected significantly higher EGF concentration in the water fraction of the lipid phase compared to the lipid fraction of lipid phase in the first 3 months of lactation. In the case of CD40, MCP-1, and RANTES we did not measure significant differences between the two layers of the lipid phase during the first 3 months of breastfeeding. During the second part of the examination period, we detected significantly higher CD40, EGF, and MCP-1 concentrations in the water phase compared to the water fraction of the lipid phase. In all cases, the water phase contained significantly increased levels of factors compared to the lipid fraction of lipid phase. When we compared the two layers of the lipid phase, the water fraction of the lipid phase contained significantly higher EGF and RANTES concentrations compared to the lipid fraction of the lipid phase. We did not find differences in CD40 or MCP-1 level between the two layers of lipid phase between the $4^{\text {th }}$ and $6^{\text {th }}$ months (Fig. 1).

\section{Discussion}

In the present study, we detected several bioactive factors during the first 6 months of lactation in the three separated layers of human milk: in the water phase and in the water and lipid fractions of the lipid phase. Presumably each of these layers has its own role during organogenesis. The content of the water phase affects the infant's body through mucosal absorption from the oral cavity. The bioactive components in the MFG, because of the protective lipid layer, directly affect the lower gastrointestinal tract, and through the circulation they may affect the developing human body [10]. Cytokines and chemokines are small soluble factors that modulate biological 
Table 4 Concentration of bioactive factors presented in the lipid phase of human milk during the first 6 months of lactation [pg/ml]

\begin{tabular}{|c|c|c|c|c|c|c|}
\hline \multirow[t]{3}{*}{ Factors } & \multicolumn{6}{|l|}{ Lipid phase [L] } \\
\hline & \multicolumn{3}{|c|}{ Water fraction [L-WF] } & \multicolumn{3}{|c|}{ Lipid fraction [L-LF] } \\
\hline & $1-3$ months & $4-6$ months & $\begin{array}{l}p \text {-values } \\
1-3 \text { vs } 4-6 \text { mo }\end{array}$ & $1-3$ months & 4-6 months & $\begin{array}{l}p \text { - values } \\
1-3 \text { vs } 4-6 \text { mo }\end{array}$ \\
\hline CD40 & $22.87 \pm 7.36$ & $34.11 \pm 6.67$ & 0.019 & $22.98 \pm 7.87$ & $29.80 \pm 0.01$ & 0.1330 \\
\hline EGF & $828.48 \pm 480.11$ & $1851.26 \pm 456.69$ & $<0.0001$ & $375.25 \pm 129.18$ & $669.11 \pm 197.70$ & $<0.0001$ \\
\hline MCP-1 & $13.02 \pm 3.49$ & $21.41 \pm 9.71$ & 0.0245 & $5.07 \pm 0.69$ & $10.67 \pm 6.01$ & 0.0020 \\
\hline RANTES & $3.13 \pm 0.73$ & $4.34 \pm 0.59$ & $<0.0001$ & $3.65 \pm 1.86$ & $2.37 \pm 0.0$ & 0.2031 \\
\hline
\end{tabular}

CD40 cluster of differentiation 40; EGF epidermal growth factor; MCP-1 macrophage chemokine protein-1; RANTES regulated on activation, normal T cell expressed and secreted; mo months

signals with remarkable capabilities, such as influencing growth and development, hematopoiesis, and the immune system through lymphocyte recruitment, $\mathrm{T}$ cell subset differentiation and inflammation $[29,30]$.

During postnatal adaptation, the gastrointestinal tract becomes more actively involved in enteral nutrition [31]. Several research groups have proven that the microbiome in infants is an important regulator of developing subsistence. The human microbiome is a constantly changing system influenced by hormones, cytokines, and chemokines. Its development starts at the moment of birth, and the most important changes occur during the first year of life [32-35]. The connections between the brain and gut have been investigated previously; this communication axis bound by the vagus nerve is described as the microbiota-gut-vagus-brain axis [36]. Studies have proven the connection of the microbiome to disorders such as visceral pain, autism spectrum disorder, cardiovascular risk, obesity, depression, and sclerosis multiplex [36]. Previous studies suggest that the gut microbiome modulates molecular mechanisms that influence allergic reactions [37].

The composition of human milk influences the developing immune system in the early, critical period of postnatal adaptation [38]. Cytokines and chemokines in breast milk reach the neonatal intestines intact due to the protection from digestion by protease inhibitors, such as alpha 1-antichymotrypsin and alpha 1-antitrypsin, which are present in human milk. In addition, the gastric digestion of proteins is reduced during the first 3 months of life because of the limited secretion of pepsin and hydrogen ions and the general immaturity of the newborn's digestive abilities. Therefore, these factors can exert their biological activities in their intact form [39, 40].

Several cytokines are known to play important roles in the brain, because they are transported across the blood-brain barrier [41]; the rate of transport varies among regions and is affected by cellular components of the blood [42]. The cytokines and chemokines affect cellular and molecular processes of hippocampal-dependent long-term memory consolidation and neurogenesis [43]. Chemokines are involved in neurodevelopment and neurophysiological signaling, and they attract leukocytes and mediate immune responses in the brain [44].

GRO is a small cytokine belonging to the CXC chemokine family that was previously called GRO1 oncogene, and now it is called CXCL1. GRO is expressed physiologically during protective reactions against microbiological agents or tumor progression [45]. GRO's chemoattractant function in neutrophil granulocytes has been described earlier [18] and it is also known as a mediator of inflammatory responses [46]. We detected high amount of GRO in every phase of breast milk as Radillo and coworkers found in whole milk samples [47]. It is suggested that GRO may moderate the development of gut-associated lymphoid tissue. In neovascularization GRO is necessary for ideal endothelial cell proliferation [24]. Hence, it may directly affect the vascularization of the intestinal wall and through absorption also the extraintestinal vessels of the body.

Eotaxin, a member of the CC chemokine subfamily, was present in low concentration in the water phase of human milk. Previous examinations proved its role in neurogenesis [25] and plasticity [48]. Other investigators reported higher concentration of eotaxin in colostrum and in the first week of lactation $[49,50]$. It is possible that the concentration of eotaxin fluctuates with time since in our examination this factor was present in low concentration in every layer. Although it is able to be transported through the blood-brain-barrier [41], this factor in these low concentrations may have little effect on the development of the brain.

A constitutively expressed chemokine named fractalkine in humans and neurotactin in mice [51] is a member of the $\mathrm{CX}_{3} \mathrm{C}$ chemokine family. Experiments pointed out that fractalkine promotes synaptic plasticity in the developing nervous system. It modulates synaptic transmission and has long-term potentiation in the hippocampus [26]. Fractalkine is upregulated in the hippocampus; it also regulates spatial orientation learning processes. Based on our work, fractalkine is present in higher concentrations in the different milk layers than what others have reported in whole milk [52]. In summary, fractalkine reaches different parts of the developing 
1-3 MONTHS

1A

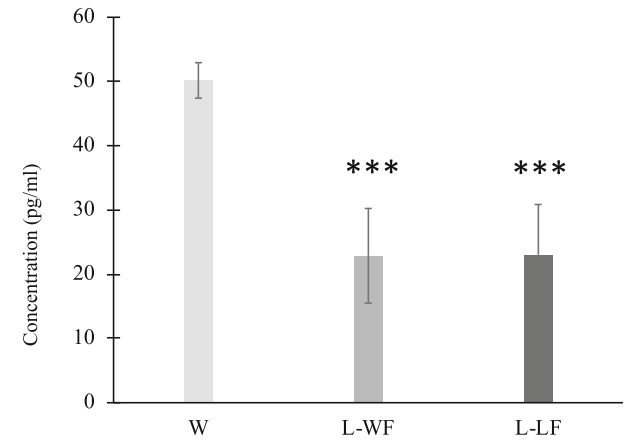

1B

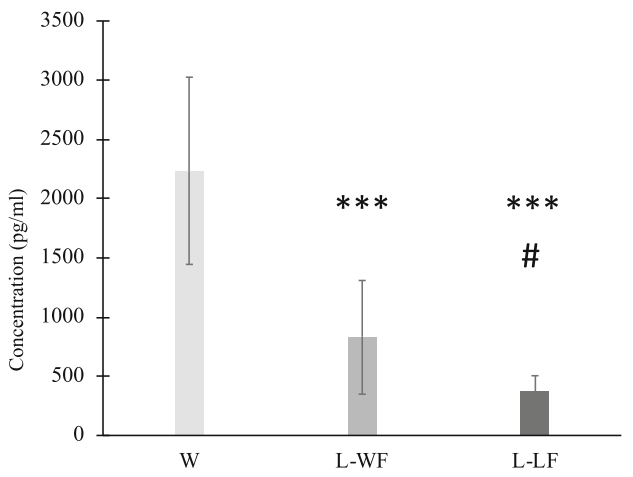

$1 \mathrm{C}$

MCP-1

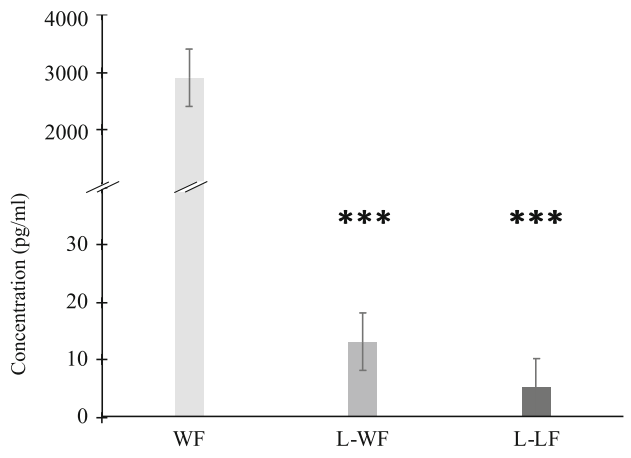

1D
RANTES

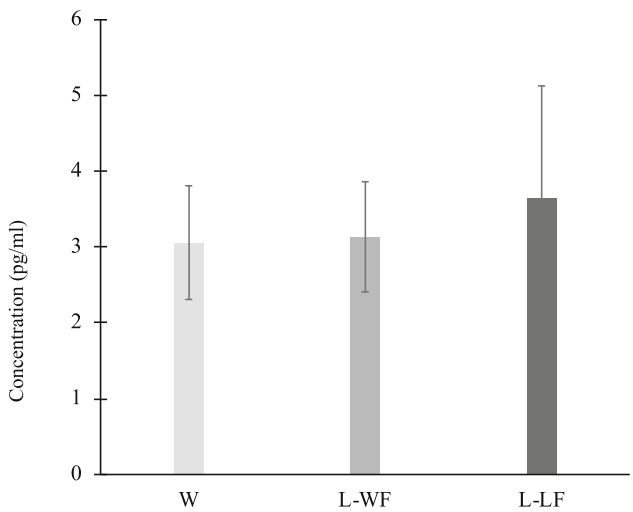

4-6 MONTHS
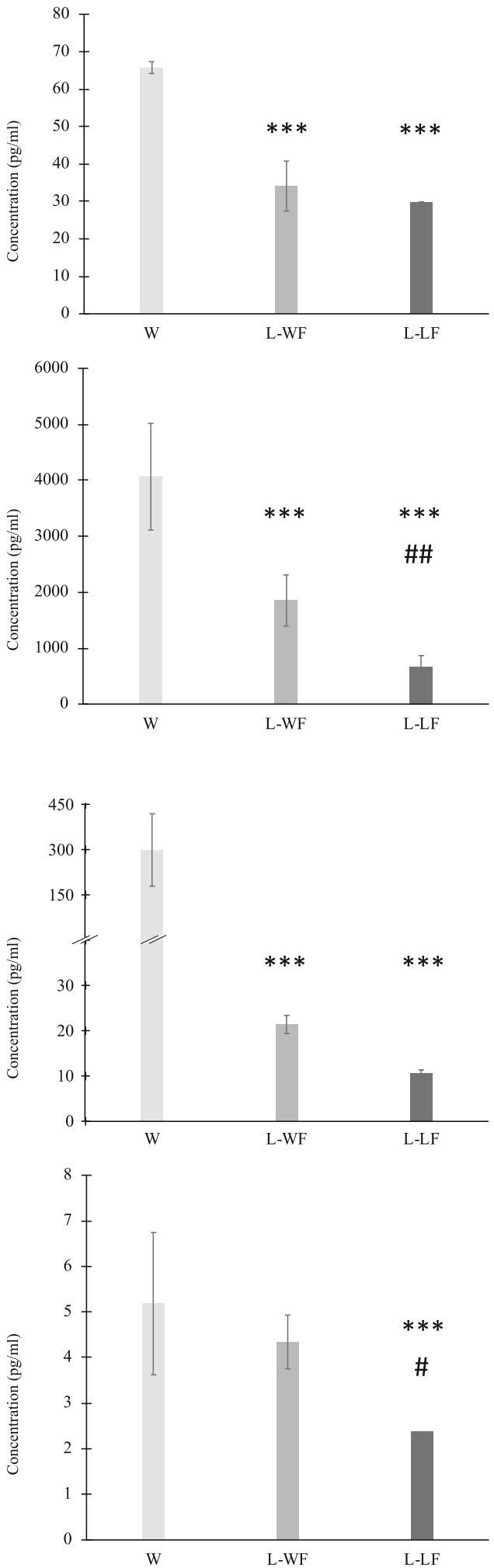

Fig. 1 (See legend on next page.) 
(See figure on previous page.)

Fig. 1 Concentration of CD40, RANTES, MCP-1 and EGF between the 1-3 and 4-6 months of lactation in the three separated layers of breast milk: water phase [W], water fraction of lipid phase [L-WF] and lipid fraction of lipid phase [L-LF]. 1A: CD40; 1B: EGF; 1C: MCP-1; 1D: RANTES. a CD40**P $<0.0001$ Vs W, b EGF **P $<0.0001$ vs W, \#\#P<0.01 vs L-WF, \#P<0.05 vs L-WF, c MCP-1 ${ }^{* *} P<0.0001$ vs W, d RANTES ${ }^{* * *} P<0.0001$ vs W, \#P $<0.05$ vs L-WF. Note. CD40 = cluster of differentiation 40; MCP-1 = macrophage chemokine protein-1; RANTES = regulated on activation, normal T cell expressed and secreted; EGF = epidermal growth factor

human body through absorption and it may modulate neurodevelopment.

The monocyte chemoattractant protein 1 (MCP-1) or CCL2 (chemokine [C-C motif] ligand 2) is an inducible cytokine. It is produced by endothelial and epithelial cells, and fibroblasts and induced by oxidative stress, growth factors, and other cytokines [53, 54]. MCP-1 regulates the migration of monocytes, natural killer (NK) cells, and memory T-lymphocytes [21]. During the first 3 months of lactation, we detected high levels of MCP-1, which dramatically decreased from the $4^{\text {th }}$ month; we suggest that this factor particularly plays a role in the early adaptation of immune system as an influencer of $\mathrm{T}$ cell immunity [55-57]. This protein was reported to be present in different concentration in colostrum and mature milk samples $[49,50,58-60]$. Our results show that the water phase contained an order of magnitude higher level of MCP-1 compared to the lipid phase, especially in the first 3 months of lactation. We hypothesize that the presence of this factor influences the early postnatal adaptation of the immune system, mainly the gut-associated lymphatic tissue (GALT).

One of the selected chemokines, RANTES, modulates the homing and trafficking of monocytes and T-cells. The presence of RANTES in non-lactating mammary epithelial cells was proven with immunohistochemistry [60]. It plays a role in chemotaxis and also promotes leukocyte infiltration during inflammation [61]. Previous examinations measured elevated values in early lactation $[49,58,62]$. Since in breast milk we detected RANTES only in low concentrations, we suggest that it has little immunological impact.

Two of the examined factors were cytokines, CD40 and Flt-3L. CD40 is expressed by a variety of cells, such as monocytes, B-cells, antigen presenting cells, endothelial cells, smooth muscle cells, and fibroblasts [63]. Presumably, the maternal T-cells interact with $\mathrm{B}$ cells of the newborn and stimulate the immune system because T-cells of infants are immature. Presumably, CD40 plays a role in the immunological adaptation of the adequate immune responses to unknown agents.

We also examined the growth factor EGF, which was present in one of the highest concentrations among the analyzed bioactive factors in the 3 layers of human milk. The level of EGF in colostrum is 2000 times higher than in maternal serum and 100 times higher than in foremilk [27]. Based on previous examinations EGF is resistant against low $\mathrm{pH}$ and digestive enzymes. Therefore, the water phase of milk may reach the surface of epithelium in the whole length of the gastrointestinal tract. Due to immature cell connections of the epithelium, EGF can spread into the circulation $[64,65]$. EGF stimulates DNA synthesis of enterocytes and enables their differentiation $[66,67]$.

To our knowledge, no data exist about the presence of Flt-3L and MDC in breast milk. Lyman and coworkers previously proved that Flt-3L stimulates the primitive hematopoietic stem cell progenitors' proliferation [23] and it also promotes $\mathrm{T}$ cell activation [68]. Since this factor can be absorbed into the circulation, the question is raised whether it may participate in the development of the hematopoietic system and in the development of adaptive immunity.

One of the constitutively expressed chemokines is MDC, the expression of which is enhanced by lipopolysaccharides and primary proinflammatory cytokines in macrophages [69]; it is also produced by thymus epithelial cells and expressed by the hematopoietic system [70]. The production of MDC has been observed in Th1 and Th2 cells [20], and it plays a role in type II reactions in atopic dermatitis in humans [71]. We measured the chemokine MIP- $1 ß$ in low concentration as in a previous study [72]. MIP-1ß is crucial for the development of appropriate immune responses and the mediation of inflammation [22]. It is a potent chemoattractant of $\mathrm{T}$ lymphocytes and attracts exclusively activated T-cells [73]. In human milk, MDC and MIP-1ß are presumably playing important roles in the adaptation of immune system through the differentiation of $\mathrm{T}$ cells and may influence the development of T-cell mediated immune responses.

\section{Conclusions}

Milk provides not only the building blocks for development but also the endocrinological and hormonal signals that contribute to the biophysiological organization of the infant. The separation of human milk into different fractions enables analyzing the presence and concentration of various bioactive factors that may be present in low concentrations in human milk yet have significant biological effects. The present study showed that the water phase is not the only influential part of breast milk, but the MFGs in the lipid layer contain important bioactive compounds. Our analysis provides a more 
complete picture of the fluctuating levels of factors in breast milk since we measured the composition of breast milk through the first 6 months of life. Based on our work, EGF and the analyzed cytokines and chemokines are present in breast milk during the first 6 months of lactation, including Flt-3L and MDC, which have not previously been reported as present in breast milk. These agents may be absorbed from the oral cavity from the water phase of human milk and they can spread to every organ of the infant. Factors present in the lipid fraction are protected, so they are able to reach the lower gastrointestinal tract where they may have a local effect on gut mucosa or systemic effects through absorption into the circulation. Further research will be required to detect the concentration ranges within which these factors are essential and beneficial for the development of newborns.

\section{Abbreviations}

BMI: Body Mass Index; CCL2: Chemokine (C-C motif) ligand 2; CD40: Soluble cluster of differentiation 40 ligand; $C X C, C X C L 1, C C, C X{ }_{3}$ C: Chemokine subfamilies; EGF: Epidermal growth factor; Flt-3L: FMS-like tyrosine kinase 3 ligand; GALT: Gut-associated lymphatic tissue; Gl: Gastrointestinal tract; GRO: Growth-regulated oncogene; MCP-1: Monocyte chemoattractant protein-1; MDC: Macrophage-derived chemokine; MFG: Milk fat globules; MIP-1 $\beta$ : Macrophage inflammatory protein-1 beta; PBS: Phosphate buffered saline; RANTES: Regulated on activation, normal T cell expressed and secreted

\section{Acknowledgements}

We are grateful to the women who participated in this study and we wish to thank Ibolya Tarcai and her coworkers at the Unified Health Institutions of Pécs and associates of the Department of Obstetrics and Gynaecology, Department of Anatomy, Department of Biochemistry and Medical Chemistry their help and support during our project. We acknowledge Prof. Edward F. Bell for his advice and help in editing the manuscript.

\section{Funding}

This study was funded by the Hungarian Scientific Research Fund K119759, K115874; GINOP-2.3.2-15-2016-00050 "PEPSYS"; EFOP-3.6.3-VEKOP-16-15 2017-00008; Hungarian Brain Research Program 2017-1.2.1-NKP-2017-00002; EFOP-3.6.2-16-2017-00008 "The role of neuro-inflammation in neurodegeneration: from molecules to clinics"; University of Pécs Medical School KA Research Grant; TAMOP-4.2.4.A/2-11-1-2012-0001; New Hungarian National Excellence Program UNKP-16-4-IV, ÚNKP-16-2-I, ÚNKP-2017-2, ÚNKP-2018-3-I, ÚNKP-2018-4; Hungarian Academy of Sciences MTA-TKI-14016; University of Pécs Ildikó Kriszbacher Scholarship; Higher Education Institutional Excellence Programme of the Ministry of Human Capacities in Hungary; 20765-3/2018/ FEKUTSTRAT; EFOP-3.6.3-VEKOP-16-2017-00009. AK and AT were supported by the János Bolyai Research Scholarship of the Hungarian Academy of Sciences.

\section{Availability of data and materials}

The datasets of the study are available from the authors on reasonable request.

\section{Authors' contributions}

RAV and AT made the conception of research protocol, literature review, collected milk samples, drafted manuscript and with TD performed statistical analysis. RAV and AK analyzed milk samples. AT, DR, AJ and TE consulted and gave critical revision. All authors read and approved the final manuscript. AT and DR provided the financial support.

\section{Ethics approval and consent to participate}

The study was approved by Regional Ethical Committee for Science: PTE KK 6383 University of Pécs. Written informed consents were obtained from all the participants.

\section{Consent for publication}

Not applicable.

\section{Competing interests}

The authors declare that they have no competing interests.

\section{Publisher's Note}

Springer Nature remains neutral with regard to jurisdictional claims in published maps and institutional affiliations.

\section{Author details}

${ }^{1}$ Department of Anatomy, MTA-PTE PACAP Research Group, Centre for Neuroscience, Medical School, University of Pécs, Pécs, Hungary.

${ }^{2}$ Department of Pharmacology and Pharmacotherapy; Medical School, University of Pécs, Pécs, Hungary. ${ }^{3}$ Department of Medical Biology and Central Electron Microscope Laboratory, Medical School, University of Pécs, Pécs, Hungary. ${ }^{4}$ Institute of Bioanalysis, Medical School, University of Pécs, Pécs, Hungary. ${ }^{5}$ Department of Obstetrics and Gynaecology, Medical School, University of Pécs, Pécs, Hungary.

Received: 24 July 2018 Accepted: 29 January 2019

Published online: 11 February 2019

\section{References}

1. Catinella S, Traldi P, Pinelli C, Dallaturca E, Marsilio R. Matrix-assisted laser desorption/ionization mass spectrometry in milk science. Rapid Commun Mass Spectrom. 1996;10(9):1629-37.

2. Young BE, Levek C, Reynolds RM, Rudolph MC, MacLean P, Hernandez TL, et al. Bioactive components in human milk are differentially associated with rates of lean and fat mass deposition in infants of mothers with normal vs. elevated BMI. Pediatr Obes. 2018;13(10):598-6.

3. Nasser R, Stephen AM, Goh YK, Clandinin MT. The effect of a controlled manipulation of maternal dietary fat intake on medium and long chain fatty acids in human breast milk in Saskatoon, Canada. Int Breastfeed J. 2010;5:3.

4. Schrezenmeir J, Korhonen H, Williams C, Gill HS, Shah N. Foreword. Br J Nutr. 2000;84(S1):1.

5. Freitas NA, Santiago LTC, Kurokawa CS, Meira Junior JD, Corrente JE, Rugolo LMSS. Effect of preeclampsia on human milk cytokine levels. J Matern Fetal Neonatal Med. 2018. https://doi.org/10.1080/14767058.2018.1429395 Epub ahead of print.

6. Goldman AS. Modulation of the gastrointestinal tract of infants by human milk. Interfaces and interactions. An evolutionary perspective. J Nutr. 2000; 130(2S Suppl):426S-31S.

7. Hajeebhoy N, Nguyen PH, Mannava P, Nguyen TT, Mai LT. Suboptimal breastfeeding practices are associated with infant illness in Vietnam. Int Breastfeed J. 2014:9:12.

8. Gao X, McMahon RJ, Woo JG, Davidson BS, Morrow AL, Zhang Q. Temporal changes in milk proteomes reveal developing milk functions. J Proteome Res. 2012;11(7):3897-907.

9. Moossavi S, Miliku K, Sepehri S, Khafipour E, Azad MB. The prebiotic and probiotic properties of human milk: implications for infant immune development and pediatric asthma. Front Pediatr. 2018;6:197.

10. Ballard O, Morrow AL. Human milk composition: nutrients and bioactive factors. Pediatr Clin North Am. 2013;60(1):49-74.

11. Basch JJ, Greenberg R, Farrell HM. Identification of the milk fat globule membrane proteins. II. Isolation of major proteins from electrophoretic gels and comparison of their amino acid compositions. Biochim Biophys Acta. 1985;830(2):127-35.

12. Garcia C, Innis S. Structure of the human milk fat globule. Lipid Technol. 2013;25(10):223-6.

13. Michalski MC, Cariou R, Michel F, Garnier C. Native vs. damaged milk fat globules: membrane properties affect the viscoelasticity of milk gels. J Dairy Sci. 2002;85(10):2451-61.

14. Patton S, Keenan TW. The milk fat globule membrane. Biochim Biophys Acta. 1975;415(3):273-309. 
15. Timby N, Hernell O, Vaarala O, Melin M, Lönnerdal B, Domellöf M. Infections in infants fed formula supplemented with bovine milk fat globule membranes. J Pediatr Gastroenterol Nutr. 2015;60(3):384-9.

16. Lopez C. Milk fat globules enveloped by their biological membrane: unique colloidal assemblies with a specific composition and structure. Curr Opin Colloid Interface Sci. 2011;16:391-404.

17. Gregory KE, Samuel BS, Houghteling P, Shan G, Ausubel FM, Sadreyev RI, Walker WA. Influence of maternal breast milk ingestion on acquisition of the intestinal microbiome in preterm infants. Microbiome. 2016;4(1):68.

18. Moser B, Clark-Lewis I, Zwahlen R, Baggiolini M. Neutrophil-activating properties of the melanoma growth-stimulatory activity. J Exp Med. 1990; 171(5):1797-802.

19. Becker S, Quay J, Koren HS, Haskill JS. Constitutive and stimulated MCP-1, GRO alpha, beta, and gamma expression in human airway epithelium and bronchoalveolar macrophages. Am J Phys. 1994;266(3Pt1):L278-86.

20. Mantovani A. The chemokine system: redundancy for robust outputs. Immunol. 1999:20(6):254-7.

21. Spoettl T, Hausmann M, Herlyn M, Gunckel M, Dirmeier A, Falk W, et al. Monocyte chemoattractant protein-1 (MCP-1) inhibits the intestinal-like differentiation of monocytes. Clin Exp Immunol. 2006;145(1):190-9.

22. Ren M, Guo Q, Guo L, Lenz M, Qian F, Koenen RR, et al. Polymerization of MIP-1 chemokine (CCL3 and CCL4) and clearance of MIP-1 by insulindegrading enzyme. EMBO J. 2010;29(32):3952-66.

23. Lyman SD, James L, Johnson L, Brasel K, de Vries P, Escobar SS, et al. Cloning of the human homologue of the murine flt3 ligand: a growth factor for early hematopoietic progenitor cells. Blood. 1994;83(10):2795-801.

24. Miyake M, Goodison S, Urquidi V, Gomes Giacoia E, Rosser CJ. Expression of CXCL1 in human endothelial cells induces angiogenesis through the CXCR2 receptor and the ERK1/2 and EGF pathways. Lab Investig. 2013;93(7):768-78.

25. Villeda SA, Luo J, Mosher Kl, Zou B, Britschgi M, Bieri G, et al. The ageing systemic milieu negatively regulates neurogenesis and cognitive function. Nature. 2011:477(7362):90-4.

26. Sheridan GK, Wdowicz A, Pickering M, Watters O, Halley P, O'Sullivan NC, et al. CX3CL1 is up-regulated in the rat hippocampus during memoryassociated synaptic plasticity. Front Cell Neurosci. 2014;8:233.

27. Dvorak B, Fituch CC, Williams CS, Hurst NM, Schanler RJ. Concentrations of epidermal growth factor and transforming growth factor-alpha in preterm milk. Adv Exp Med Biol. 2004;554:407-9.

28. Kent JC, Mitoulas LR, Cregan MD, Ramsay DT, Doherty DA, Hartmann PE. Volume and frequency of breastfeedings and fat content of breast milk throughout the day. Pediatrics. 2006;117(3):e387-95.

29. Chen ML, Sundrud MS. Cytokine networks and T cell subsets in inflammatory bowel diseases. Inflamm Bowel Dis. 2016;22(5):1157-67.

30. Imam T, Park S, Kaplan MH, Olson MR. Effector T helper cell subsets in inflammatory bowel diseases. Front Immunol. 2018;9:1212.

31. Wagner CL, Taylor SN, Johnson D. Host factors in amniotic fluid and breast milk that contribute to gut maturation. Clin Rev Allergy Immunol. 2008; 34(2):191-204

32. Pacha J. Development of intestinal transport function in mammals. Physiol Rev. 2000;80(4):1633-67.

33. Rodríguez JM, Murphy K, Stanton C, Ross RP, Kober Ol, Juge N, et al. The composition of the gut microbiota throughout life, with an emphasis on early life. Microb Ecol Health Dis. 2015;26:26050.

34. Cacho NT, Lawrence RM. Innate immunity and breast milk. Front Immunol. 2017;8:584.

35. Heimesaat MM, Reifenberger G, Vicena V, Illes A, Horvath G, Tamas A, et al. Intestinal microbiota changes in mice lacking pituitary adenylate cyclase activating polypeptide (PACAP) - Bifidobacteria make the difference. Eur J Microbiol Immunol. 2017;7(3):187-99.

36. Montiel-Castro AJ, González-Cervantes RM, Bravo-Ruiseco G, Pacheco-López G. The microbiota-gut-brain axis: neurobehavioral correlates, health and sociality. Front Integr Neurosci. 2013;7:70.

37. van $\operatorname{der}$ Leek AP, Yanishevsky Y, Kozyrskyj AL. The kynurenine pathway as a novel link between allergy and the gut microbiome. Front Immunol. 2017;8:1374.

38. Newburg DS, Walker WA. Protection of the neonate by the innate immune system of developing gut and of human milk. Pediatr Res. 2007;61(1):2-8.

39. Weaver $L$, Laker M, Nelson R. Intestinal permeability in the newborn. Arch Dis Child. 1984;59(3):236-41.

40. Oguchi S, Shinohara K, Yamashiro Y, Walker W, Sanderson I. Growth factors in breast milk and their effect on gastrointestinal development. Zhonghua Min Guo Xiao Er Ke Yi Xue Hui Za Zhi. 1997;38(5):332-7.
41. Banks WA. Blood-brain barrier transport of cytokines: a mechanism for neuropathology. Curr Pharm Des. 2005;11(8):973-84.

42. Erickson MA, Morofuji Y, Owen JB, Banks WA. Rapid transport of CCL11 across the blood-brain barrier: regional variation and importance of blood cells. J Pharmacol Exp Ther. 2014;349(3):497-507.

43. Hopkins SJ, Rothwell NJ. Cytokines and the nervous system. I: expression and recognition. Trends Neurosci. 1995;18(2):83-8.

44. Bieber AJ, Warrington A, Asakura K, Ciric B, Kaveri SV, Pease LR, et al. Human antibodies accelerate the rate of remyelination following lysolecithininduced demyelination in mice. Glia. 2002;37(3):241-9.

45. Sepuru KM, Rajarathnam K. CXCL1/MGSA is a novel glycosaminoglycan (GAG)-binding chemokine: structural evidence for two distinct nonoverlapping binding domains. J Biol Chem. 2016;291(8):4247-55.

46. Gasperini S, Calzetti F, Russo MP, De Gironcoli M, Cassatella MA. Regulation of GRO alpha production in human granulocytes. J Inflamm. 1995;45(3):143-51.

47. Radillo O, Norcio A, Addobbati R, Zauli G. Presence of CTAK/CCL27, MCP-3/ CCL7 and LIF in human colostrum and breast milk. Cytokine. 2013;61(1):26-8.

48. Bloch J, Kaeser M, Sadeghi Y, Rouiller EM, Redmond DE Jr, Brunet JF Doublecortin-positive cells in the adult primate cerebral cortex and possible role in brain plasticity and development. J Comp Neurol. 2011;519(4):775-89.

49. Zizka J, Kverka M, Novotná O, Stanková I, Lodinová-Zádníková R, Kocourková I, et al. Perinatal period cytokines related to increased risk of future allergy development. Folia Microbiol (Praha). 2007;52(5):549-55.

50. Groër MW, Shelton MM. Exercise is associated with elevated proinflammatory cytokines in human milk. J Obstet Gynecol Neonatal Nurs. 2009;38(1):35-41.

51. Pan Y, Lloyd C, Zhou H, Dolich S, Deeds J, Gonzalo JA, et al. Neurotactin, a membrane-anchored chemokine upregulated in brain inflammation. Nature. 1997;387(6633):611-7.

52. Aparicio VA, Ocón O, Diaz-Castro J, Acosta-Manzano P, Coll-Risco I, BorgesCósic $M$, et al. Influence of a concurrent exercise training program during pregnancy on colostrum and mature human milk inflammatory markers: findings from the GESTAFIT project. J Hum Lact. 2018;34(4):789-98.

53. Cushing SD, Berliner JA, Valente AJ, Territo MC, Navab M, Parhami F, et al. Minimally modified low density lipoprotein induces monocyte chemotactic protein 1 in human endothelial cells and smooth muscle cells. Proc Natl Acad Sci U S A. 1990;87(13):5134-8.

54. Barna BP, Pettay J, Barnett GH, Zhou P, Iwasaki K, Estes ML. Regulation of monocyte chemoattractant protein-1 expression in adult human nonneoplastic astrocytes is sensitive to tumor necrosis factor (TNF) or antibody to the 55 kDa TNF receptor. J Neuroimmunol. 1994;50(1):101-7.

55. Chensue SW, Warmington KS, Lukacs NW, Lincoln PM, Burdick MD, Stricter RM, et al. Monocyte chemotactic protein expression during schistosome egg granuloma formation. Sequence of production, localization, contribution, and regulation. Am J Pathol. 1995;146(1):130-8.

56. Handel TM, Domaille PJ. Heteronuclear (1H, 13C, 15N) NMR assignments and solution structure of the monocyte chemoattractant protein-1 (MCP-1) dimer. Biochemistry. 1996;35(21):6569-84.

57. Gu L, Tseng S, Horner RM, Tam C, Loda M, Rollins BJ. Control of TH2 polarization by the chemokine monocyte chemoattractant protein-1. Nature. 2000;404(6776):407-11.

58. Srivastava MD, Brouhard B, Saneto R, Groh-Wargo S, Kubit J. Cytokines in human milk. Res Commun Mol Pathol Pharmacol. 1996:93(23):263-87.

59. Kverka M, Burianova J, Lodinova-Zadnikova R, Kocourkova I, Cinova J, Tuckova $\mathrm{L}$, et al. Cytokine profiling in human colostrum and milk by protein array. Clin Chem. 2007;53(5):955-62.

60. Michie CA, Tantscher E, Schall T, Rot A. Physiological secretion of chemokines in human breast milk. Eur Cytokine Netw. 1998;9(2):123-9.

61. Appay V, Rowland-Jones SL. RANTES: a versatile and controversial chemokine. Trends Immunol. 2001;22(22):83-7.

62. Böttcher MF, Jenmalm MC, Björksten B, Garofalo RP. Chemoattractant factors in breast milk from allergic and nonallergic mothers. Pediatr Res. 2000;47(5):592-7.

63. Chatzigeorgiou A, Lyberi M, Chatzilymperis G, Nezos A, Kamper E. CD40 CD40L signaling and its implication in health and disease. Biofactors. 2009; 35(6):474-83.

64. Barnard JA, Beauchamp RD, Russell WE, Dubois RN, Coffey RJ. Epidermal growth factor-related peptides and their relevance to gastrointestinal pathophysiology. Gastroenterology. 1995;108(2):564-80.

65. Playford RJ, Wright NA. Why is epidermal growth factor present in the gut lumen? Gut. 1996;38(3):303-5. 
66. Read LC, Upton FM, Francis GL, Wallace JC, Dahlenberg GW, Ballard FJ. Changes in growth promoting activity of human milk during lactation Pediatr Res. 1984;18(2):133-9.

67. Chang CY, Chao JCJ. Effect of human milk and epidermal growth factor on growth of human intestinal CaCo-2 cells. J Pediatr Gastroenterol Nutr. 2002; 34(4):394-401.

68. Guermonprez P, Helft J, Claser C, Deroubaix S, Karanje H, Gazumyan A, et al. Inflammatory Flt3l is essential to mobilize dendritic cells and for T cell responses during Plasmodium infection. Nat Med. 2013;19(6):730-8.

69. Rodenburg RJT, Brinkhuis RFB, Peek R, Westphal JR, van Den Hoogen FHJ, van Venrooij WJ, et al. Expression of macrophage-derived chemokine (MDC) mRNA in macrophages is enhanced by interleukin-1 $\beta$, tumor necrosis factor a, and lipopolysaccharide. J Leukoc Biol. 1998;63(5):606-11.

70. Mantovani A, Gray PA, Van Damme J, Sozzani S. Macrophage-derived chemokine (MDC). J Leukoc Biol. 2000;68(3):400-4.

71. Galli G, Chantry D, Annunziato F, Romagnani P, Cosmi L, Lazzeri E, et al. Macrophage-derived chemokine production by activated human $T$ cells in vitro and in vivo: preferential association with the production of type 2 cytokines. Eur J Immunol. 2000;30(1):204-10.

72. Bosire R, Guthrie BL, Lohman-Payne B, Mabuka J, Majiwa M, Wariua G, et al. Longitudinal comparison of chemokines in breast milk early postpartum among HIV-1-infected and uninfected Kenyan women. Breastfeed Med. 2007;2(3):129-38

73. Chantry D, Romagnani P, Raport CJ, Wood CL, Epp A, Romagnani S, Gray PW. Macrophage-derived chemokine is localized to thymic medullary epithelial cells and is a chemoattractant for CD3(+), CD4(+), CD8(low) thymocytes. Blood. 1999;94(6):1890-8.

Ready to submit your research? Choose BMC and benefit from:

- fast, convenient online submission

- thorough peer review by experienced researchers in your field

- rapid publication on acceptance

- support for research data, including large and complex data types

- gold Open Access which fosters wider collaboration and increased citations

- maximum visibility for your research: over $100 \mathrm{M}$ website views per year

At BMC, research is always in progress.

Learn more biomedcentral.com/submissions 